\title{
PROBLEMÁTICAS Y NIVELES DE FORTUNA DE LOS MAYORDO- MOS DE PROPIOS EN EL BURGOS DEL XVIII
}

\author{
Francisco J. Sanz de la Higuera \\ I.E.S. "Torreblanca" (Sevilla), España \\ sanzdelahiguera@gmail.com
}

RESUMEN: A través de estas páginas nos acercamos a algunas de las vicisitudes e idiosincrasias de los quehaceres y niveles de fortuna de los hogares, e individuos, que asumieron la gestión de la mayordomía de Propios y rentas de la ciudad de Burgos en el Setecientos. Las peculiaridades de cómo alcanzaron dichas responsabilidades y qué características tenían sus niveles de fortuna posibilitan una reconstrucción histórica que se entronca en la "batalla" urbana incruenta, preñada de sabor a redes de influencia, por conseguir prestigio y mejoras económicas en las ciudades preindustriales españolas.

Palabras clave: Mayordomía de Propios, nivel de fortuna, Burgos, siglo XVIII.

\section{PROBLEMS AND LEVELS OF FORTUNE AMONG THE STEWARDS OF 'PROPIOS' IN BURGOS IN XVIII CENTURY}

\begin{abstract}
In this paper we will approach to some of the circumstances and conditions of the tasks and material culture of the people and families that assumed the management of the stewardship of "Propios" and rents in the city of Burgos in the eighteenth century. The features of the processes by which they achieved responsibilities and the details on their fortune levels enable a historical reconstruction that is linked to the urban struggles for prestige and wealthy positions, always in deep connection with networks of influence, in the Spanish pre-industrial cities.
\end{abstract}

Keywords: Stewards of 'Propios', fortune level, Burgos, eighteenth century.

Recibido: 27 de noviembre de 2018

Aceptado: 15 de diciembre de 2018 


\section{Introducción, fuentes documentales y aproximación bibliográfica}

Para efectuar un análisis crítico, en la medida de lo posible, del devenir de los mayordomos que gestionaron los Propios de la ciudad de Burgos a lo largo del siglo XVIII, disponemos de varias fuentes documentales. Por una parte, merced a un rastreo intensivo, y completo, de tercer nivel ${ }^{1}$, efectuado en los protocolos notariales ${ }^{2}$ y en los fondos de Concejil del Archivo Histórico Provincial de Burgos ${ }^{3}$. Por otra, también lo abordamos en función de la documentación pertinente hallada en el Archivo municipal de Burgos, en especial las Actas de Gobierno del Concejo ${ }^{4}$. En la práctica, se han recopilado, afortunadamente, 17 inventarios de bienes de un total de 41 mayordomos $^{5}$. Nos asomamos, de esa manera, al $41.5 \%$ de los niveles de fortuna de tales hogares. En los folios de las Actas de gobierno del Concejo burgalés rastreamos, en su integridad, las propuestas, el nombramiento y las fianzas necesarias para el acceso al desempeño de la mayordomía de Propios. Todo ello posibilita efectuar, en esencia, un análisis, por una parte, de las circunstancias, y peculiaridades, que hilvanaron tales quehaceres y, en especial, por otra, qué características trufaron sus niveles de fortuna.

A la postre, estas páginas constituyen una reflexión, a modo de reconstrucción histórica, de la idiosincrasia de sus hogares y de qué posición, taxonómica y estratégica, ocuparon en la sociedad urbana preindustrial en el Burgos del Setecientos (1702-1771) ${ }^{6}$ ¿ ¿Qué tipo de personas, hogares y categorías socioprofesionales se adjudicaron la gestión de dicha entidad municipal? ¿Cuáles fueron las problemáticas que generaron tensiones en la asunción de dichos quehaceres?

En las ciudades pre-industriales, en la Edad Moderna, en el Antiguo Régimen, se detecta la existencia de varias categorías de mayordomía, ya sean las

1. El rastreo intensivo de las fuentes documentales se ha realizado con el respaldo de las propuestas metodológicas generadas por CHAUNU, Pierre, "Un nouveau champ pour I'histoire sérielle: le quantitatif au trosième niveau", en Métodologie de l'histoire et des sciencies humaines, Mélanges en I'honneur de Fernand Braudel, Toulouse, 1973, tomo II, pp. 105125, GONZÁLEZ CRUZ, David, Religiosidad y ritual de la muerte en la Huelva del siglo de la Ilustración, Huelva, 1993, pp. 21-22 y GONZÁLEZ SÁNCHEZ, Carlos Alberto, El mundo del libro. Medios de difusión de la cultura occidental en las Indias en los siglos XVI y XVII, Sevilla, 2001, p. 26.

2. La documentación notarial manejada se encuentra depositada en el Archivo Histórico Provincial de Burgos. Protocolos Notariales -en lo sucesivo citado como AHPB. PN-.

3. AHPB. Concejil (C). Véanse las escrituras "de obligación y Fianza à la Maymia de propios y rentas desta Ciudad" (1728-1771).

4. En adelante AMB. Actas de gobierno (AG) (1702-1771).

5. Inventarios post-mortem, elaborados en los días posteriores al final de sus existencias.

6. Dichas fechas no son aleatorias. Dependen de que dispongamos o no de inventarios de bienes para los mayordomos del pósito. Antes de 1702 y después de 1771 no se ha localizado ninguno, lamentablemente. 
de raigambre municipal -Pósito y alhóndiga y Propios (Concejo)- o, en segundo término, de aquellas que se hallaban asociadas a instituciones eclesiásticas -la Mesa Capitular del Cabildo Catedral ${ }^{7}$, el Hospital de Barrantes ${ }^{8}$ y múltiples cofradías y conventos de la ciudad-. Me atrevo a esbozar una hipótesis de trabajo, que, como ocurre siempre en este tipo de planteamientos científicos, tiene mucho de arriesgado, de delicado y de problemático. En resumen, se plantea que la importancia de la mayordomía está relacionada, obviamente, con el prestigio, con el poder socioeconómico y con la carta de naturaleza de la entidad gestionada y con la idiosincrasia y peculiaridades de quienes asumieron su desempeño.

A mi juicio, se descubre la presencia de una escalera jerárquica de notoriedad, en función de los niveles de fortuna y la extracción socio-profesional de quienes ejercieron tales menesteres. Los ejemplos, paradigmáticos, los obtenemos de la propia realidad burgalesa $-y$, en suma, se proponen como paradigma de trabajo para el análisis de otras localidades castellanas y de otras realidades geográficas más lejanas-. Para los mayordomos del Cabildo Catedral, el promedio de sus patrimonios libres ascendía a 372.675 reales de vellón ${ }^{9}$. Los mayordomos del Hospital de Barrantes dispusieron, a su vez, de fortuna evaluadas en un promedio de $215.522 \frac{1}{1 / 2}$ reales $^{10}$. Los mayordomos del pósito y alhóndiga, en tercera instancia, disfrutaron, de promedio, de 151.909 1/2 reales, si bien las diferencias entre las categorías socio-profesionales de los mayordomos de la alhóndiga eran significativas $^{11}$. Para las mayordomías de Propios y rentas de la ciudad de Burgos en el XVIII, el promedio de los inventarios recopilados supone alrededor de los 100.000 reales. También se perciben, como se demuestra en las próximas páginas, importantes contrastes entre sus niveles de fortuna. Por lo tocante a las múltiples cofradías, hospitales, congregaciones u obras pías del entramado religioso urbano de Burgos no dispongo aún de una cuantificación exhaustiva y pormenorizada. Empero, considero que el promedio de sus patrimonios era substancialmente menor que el los anteriormente significados. Por contraste, los administradores generales de la Santa Cruzada dispusieron de un promedio bastante más suculento, con 870.647 $1 / 2$ reales de vellón ${ }^{12}$ (véase Gráfico 1 ).

7. SANZ de la HIGUERA, Francisco, "Los mayordomos de la Mesa Capitular de la Catedral de Burgos en el Setecientos (1707-1782)", Trocadero, 25, 2013, pp. 117-146.

8. SANZ de la HIGUERA, Francisco, "Aproximación a la mayordomía del Hospital de Barrantes en el Setecientos burgalés (1702-1797)", Trocadero, 28, 2016, pp. 51-77.

9. SANZ de la HIGUERA, Francisco, "Los mayordomos de la Mesa Capitular...", pp. 117-146.

10. SANZ de la HIGUERA, Francisco, "Aproximación a la mayordomía del Hospital...", pp. 51-77.

11. SANZ de la HIGUERA, Francisco, "Cultura material de los mayordomos del pósito y "Lóndiga" en el Burgos del Setecientos", Boletín de la Institución Fernán González, 257, 2018, pp. 307-325.

12. SANZ de la HIGUERA, Francisco, "La cultura material de los tesoreros generales de la Santa Cruzada en el Burgos del XVIII", Cuadernos de Estudios del siglo XVIII, 25, 2015, pp. 317-336. 


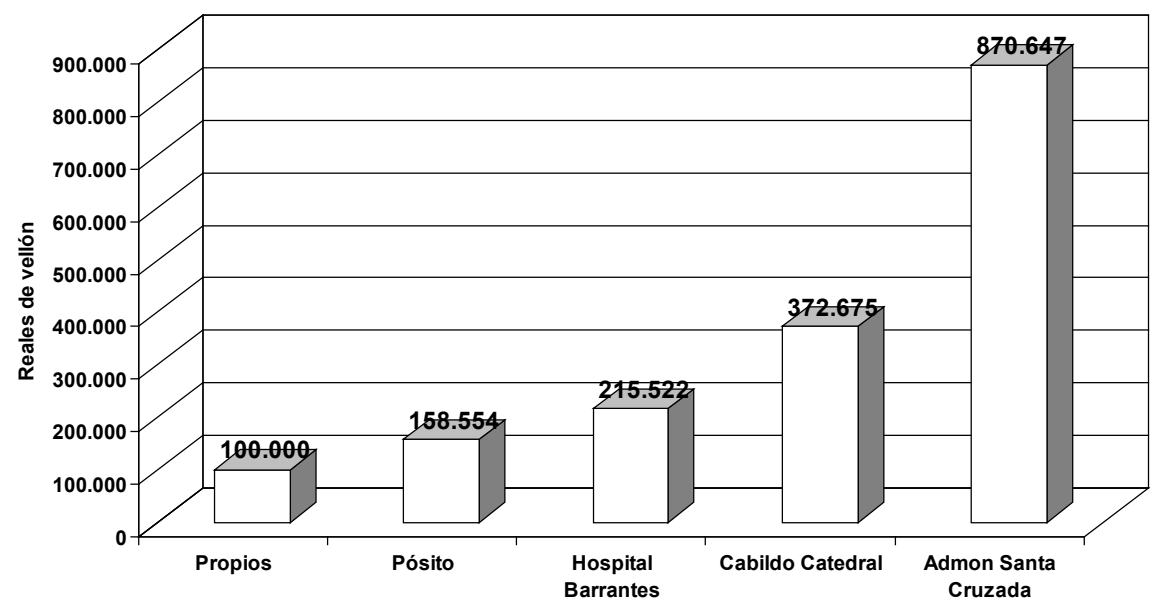

Gráfico 1. Promedio del nivel de fortuna de los mayordomos.

Es imprescindible contemplar que se aspiraba a uno u otro tipo de mayordomía en función del prestigio y de los niveles de fortuna $-y$, por tanto, de la calidad de la cultura material- del hogar, y la persona, en cada momento concreto. Cuando los componentes del Concejo nombraban al mayordomo de Propios, éste tenía la opción de renunciar, si, por lo que fuere, no se veía capacitado para ello ${ }^{13}$. Lo habitual era que asumir los quehaceres de la mayordomía supusiera un importante aldabonazo en la carrera profesional y socioeconómica de tales individuos y hogares. La participación en las redes de influencia -locales, estatales, internacionales...- eran esenciales en la construcción de una identidad familiar y personal ${ }^{14}$. Así, por ejemplo, Pedro

13. Así, por ejemplo, en 1712 -en las páginas siguientes se explicitarán más casos-, en el memorial que el nombrado mayordomo Manuel Varona eleva al Concejo solicita "que en atención a hallarse Sumamente Pobre, tanto que a no balerse de algunas comisiones hera ymposible Poder alimentarse y su dilatada familia" y que se le libere de tal compromiso, "mandando se buelba a proponer otra persona". AMB. AG. Regimiento del 2 de enero de 1712, folio 4r. Finalmente, fue "obligado", literalmente, a asumir el empleo y dar fiadores. AMB. AG. Regimiento del 16 de enero de 1712, folio 24.

14. Véanse, entre otras muchas posibilidades, IMÍZCOZ BEUNZA, José Ma (Dir.), Redes familiares y patronazgo. Aproximación al entramado social del País Vasco y Navarra en el Antiguo Régimen (siglos XV-XIX), Bilbao, 2001, IMíZCOZ BEUNZA, José Ma (Dir.), Elites, poder y red social. Las élites del País Vasco y Navarra en la Edad Moderna, Bilbao, 1996 e IMÍZCOZ BEUNZA, José M $\mathrm{M}^{\mathrm{a}}$ y OLIVERI KORTA, Oihane (Eds.), Economía doméstica y redes sociales en el Antiguo Régimen, Madrid, 2010. 
Tomé González asumió la mayordomía del Cabildo Catedral con un patrimonio de 389.048 reales de vellón $(1724)^{15}$ y la administración general de la Santa Cruzada con 1.509.477 reales $(1764)^{16}$. El modesto tendero de principios del Setecientos se transformó en un acaudalado empresario lanero y asentista Real. La adquisición de una notable cabaña de ovejas trashumantes, fórmula de inversión de los beneficios obtenidos en la mayordomía catedralicia y en el asiento de la pólvora u otros suculentos negocios, posibilitó una multiplicación significativa de sus quehaceres e implicaciones en asuntos cada vez más importantes, de mayor repercusión socioprofesional y socioeconómica. Sus niveles de fortuna responden a las inquietudes y disponibilidades de cada momento. La proyección socioeconómica y la magnitud de las redes de influencia derivadas de una y otra entidad inducen a un compromiso más localista, y por tanto cercano -léase Cabildo Catedral u Hospital de Barrantes-, o a un impacto más efervescente y expansivo, en especial por sus contactos con los dirigentes cortesanos de la capital madrileña -la Santa Cruzada tenía, en la práctica, categoría áulica, como fórmula de conexión con las estructuras dirigentes del más alto nivel del Estado borbónico- ${ }^{17}$.

En la reconstrucción de las vicisitudes protagonizadas por los mayordomos de Propios de Burgos en el discurso del Setecientos es imprescindible el concurso de un "actor secundario", el acervo bibliográfico en que hemos de sumergirnos para poder entrever, en contraste, dichas problemáticas en otras localidades y territorios. Por lo que respecta al tratamiento de las mayordomías de Propios, descuellan, entre otras muchas posibilidades, las propuestas de Salgado Olmeda $^{18}$, Hernando Ortego ${ }^{19}$, Cebreiros Álvarez ${ }^{20}$, Gutiérrez Alonso ${ }^{21}$, Bermúdez

15. AHPB. Protocolos Notariales (PN). Martín Robredo. Legajo 6964 (14 de enero de 1724), folios 340-353.

16. AHPB. Justicia Municipal (JM). Juan Antonio Fernández Guilarte. Legajo 977 (14 de julio de 1764), folios 21-127. SANZ de la HIGUERA, Francisco, "La cultura material de los tesoreros...", pp. 317-336.

17. SANZ de la HIGUERA, Francisco, "Un esperpéntico asuntillo de Estado: La casa de los Tomé en el Setecientos burgalés", en Cuadernos de Estudios del Siglo XVIII, 21, Oviedo, 2011, pp. 287-318 y "Pólvoras, municiones, lanas, granos, bulas y papel sellado (1703-1764): Don Pedro Tomé González y la hora Navarra en el Burgos del siglo XVIII", Boletín de la Institución Fernán González, 227, 2003, pp. 375-411.

18. SALGADO OLMEDA, Félix, Oligarquía urbana y gobierno de la ciudad de Guadalajara en el siglo XVIII (1718-1788), Madrid, 2000.

19. HERNANDO ORTEGO, Francisco Javier, El patrimonio municipal de Madrid en el Antiguo Régimen. Bienes de propios, comunales y baldíos, siglos XI-XVIII, Madrid, 2003.

20. CEBREIROS ÁlVAREZ, Eduardo, El municipio de Santiago de Compostela a finales del Antiguo Régimen (1759-1812), La Coruña, 1997.

21. GUTIÉRREZ ALONSO, Adriano, Estudios sobre la decadencia de Castilla. La ciudad de Valladolid en el siglo XVII, Valladolid, 1989 y "La hacienda municipal de Burgos en la época moderna. Los bienes de propios (1500-1750)", Boletín de la Institución Fernán González, 215, pp. 327-354. 
Aznar ${ }^{22}$, Cózar Gutiérrez ${ }^{23}$, Corral García ${ }^{24}$, Marina Barba ${ }^{25}$, Porres Marijuán ${ }^{26}$, Sanz Yagüe ${ }^{27}$, Irles Vicente ${ }^{28}$, Torres Sánchez ${ }^{29}$, Hernando Serra ${ }^{30}$, Guillamón Álvarez y Pérez Hervás ${ }^{31}$, García García ${ }^{32}$, Gómez Martínez ${ }^{33}$, Rubio Pérez ${ }^{34}$, Moreno Nieves ${ }^{35}$, Álvarez de Prado ${ }^{36}$, Aguirre Hueto ${ }^{37}$ o Castillo Fernández ${ }^{38}$. En lo

22. BERMÚDEZ AZNAR, Agustín, "El reformismo institucional ilustrado en el reino de Murcia durante el siglo XVIII", en Historia de la Región murciana vol. VII, Murcia, 1984, pp. 79-105.

23. CÓZAR GUTIÉRREZ, Ramón, Gobierno municipal y oligarquías. Los oficios públicos de la villa de Albacete en el siglo XVIII, Cuenca, 2008.

24. CORRAL GARCÍA, Esteban, El mayordomo de Concejo en la Corona de Castilla (s. XIII-s. XVIII), Madrid, 1991.

25. MARINA BARBA, Jesús, Poder municipal y reforma en Granada durante el siglo XVIII, Granada, 1992.

26. PORRES MARIJUÁN, Ma Rosario, Gobierno y administración de la ciudad de Vitoria en la primera mitad del siglo XVIII (Aspectos institucionales, económicos y sociales), Vitoria, 1989.

27. SANZ YAGÜE, Ana Isabel, La ciudad de Soria en el siglo XVIII. Un estudio sociocultural, Soria, 2012, Representación política y participación directa. El "policentrismo" político de Soria y la supervivencia del estado del Común en el siglo XVIII, Madrid, 2018 y "Patrimonio, cultura material y diferenciación social en la ciudad de Soria durante el siglo XVIII", Nuevo Mundo Mundos Nuevos [En línea], Coloquios, 2008 -consultado el 1 de noviembre de 2018-. URL: http://journals.openedition.org/ nuevomundo/22902.

28. IRLES VICENTE, $M^{a}$ Carmen, El régimen municipal valenciano en el siglo XVIII. Estudio institucional, Alicante, 1995.

29. TORRES SÁNCHEZ, Rafael, "Hacia un irremediable endeudamiento. La hacienda municipal de Cartagena durante el siglo XVIII", en PEREIRA IGLESIAS, José Luís, BERNARDO ARES, José Manuel y GONZÁLEZ BELTRÁN, José Manuel (Coords.), V Reunión Científica de la Asociación Española de Historia Moderna, Cádiz, 1999, tomo II, pp. 289-307.

30. HERNANDO SERRA, Ma Pilar, "Un siglo de reformas: Haciendas municipales y Reglamentos en la Valencia del XVIII", AHDE, 83, 2013, pp. 543-568.

31. GUILLAMÓN ÁLVAREZ, Francisco Javier y PÉREZ HERVÁS, Jesús, "Aproximación al estudio de las haciendas locales bajo Carlos III: Los propios del concejo murciano", Espacio, Tiempo y Forma, Historia Moderna, 4, 1989, pp. 341-356.

32. GARCÍA GARCÍA, Carmen, "Haciendas municipales y bienes de propios: Las reformas de Carlos III", Anales de estudios económicos y empresariales, 1, 1986, pp. 89-114.

33. GÓMEZ MARTíNEZ, Alfredo, "Cargos y oficios municipales en las ciudades de León, Zamora y salamanca durante el reinado de Carlos III", Estudios Humanísticos, 5, 2006, pp. 159-184.

34. RUBIO PÉREZ, Laureano, "Haciendas concejiles y haciendas municipales en la provincia de León durante la Edad Moderna", en BERNARDO ARES, José Manuel (Coord.), V Reunión Científica de la Asociación Española de Historia Moderna, Cádiz, 1999, tomo Il, pp. 275-289.

35. MORENO NIEVES, José A., "Estudio de la hacienda municipal a través de los libros de propios de la ciudad de Villena (1708-1766)", Revista de Historia Moderna, 13-14, 1995, pp. 207-229.

36. ÁLVAREZ de PRADO, Luís Alfredo, "Aportación al estudio de las haciendas concejiles castellanas. Los Propios y rentas de Burgos en el siglo XVIII", La ciudad de Burgos, Actas del Congreso de Historia de Burgos, Madrid, 1985, pp. 455-467.

37. AGUIRRE HUETO, Jesús Manuel, "Reglamento del consejo de propios y arbitrios de la ciudad de Burgos (1763)", La ciudad de Burgos..., pp. 479-489.

38. CASTILLO FERNÁNDEZ, Javier, "'Negocios de familia': El perfil institucional y social de los mayordomos de propios del reino de Granada (1492-1550)", Crónica Nova, 31, 2005, pp. 23-64. 
tocante a los niveles de fortuna y a la cultura material véanse, citadas sin un ánimo exhaustivo ni pretender efectuar un estado de la cuestión, los análisis y propuestas desarrolladas por Sobrado Correa ${ }^{39}$, García Fernández ${ }^{40}$, Ramos Palencia ${ }^{41}$, Bartolomé Bartolomé ${ }^{42}$, Álvarez Santaló y García-Baquero González ${ }^{43}$, Moreno Claverías $^{44}$, Sanz Yagüe ${ }^{45}$, Franco Rubio ${ }^{46}$ Maruri Villanueva ${ }^{47}$, Lick ${ }^{48}$, Shammas ${ }^{49}$,

39. SOBRADO CORREA, Hortensio, "Los inventarios post-mortem como fuente privilegiada para el estudio de la historia de la cultura material en la Edad Moderna", Hispania, 215, 2003, pp. 825-862.

40. GARCÍA FERNÁNDEZ, Máximo, "La cultura material doméstica en la Castilla del Antiguo Régimen", en GARCÍA FERNÁNDEZ, Máximo y SOBALER SECO, Ma Ángeles (Coords.), Estudios en homenaje al profesor Teófanes Egido, Valladolid, 2004, vol. II, pp. 249-270; GARCÍA FERNÁNDEZ, Máximo (Dir.), Cultura material y vida cotidiana moderna: escenarios, Madrid, 2013; DOS GUIMARAES SÁ, Isabel y GARCÍA FERNANDEZ, Máximo (Dirs.), Portas adentro: comer, vestir, habitar (ss. XVI-XIX), Coimbra-Valladolid, 2010 y BARTOLOMÉ BARTOLOMÉ, Juan Manuel y GARCÍA FERNÁNDEZ, Máximo (Dirs.), Apariencias contrastadas: contraste de apariencias, León, 2012.

41. RAMOS PALENCIA, Fernando, Pautas de consumo y mercado en Castilla, 1750-1850. Economía familiar en Palencia al final del Antiguo Régimen, Madrid, 2010.

42. BARTOLOMÉ BARTOLOMÉ, Juan Manuel, Interiores domésticos y condiciones de vida de las familias burguesas y nobles de la ciudad de León a finales del Antiguo Régimen (1700-1850), León, 2017.

43. De entre sus muchas, y excelentes, aportaciones descuellan, en especial, ÁLVAREZ SANTALÓ, León Carlos y GARCÍA-BAQUERO GONZÁLEZ, Antonio, "La nobleza titulada en Sevilla, 1700-1834 (Aportación al estudio de sus niveles de vida y fortuna)", en Historia, Instituciones, Documentos, 7, Sevilla, 1980, pp. 125-167, "Los comerciantes de la Carrera de Indias en la Sevilla del siglo XVIII: el diseño notarial de sus fortunas y estatus", en GARCÍA HURTADO, Manuel-Reyes (Ed.), Modernitas. Estudios en Homenaje al Profesor Baudilio Barreiro Mallón, La Coruña, 2008, p. 273-308 y "Funcionalidad del capital andaluz en vísperas de la primera industrialización", en Estudios Regionales, 5, Sevilla, 1980, pp. 101-134.

44. MORENO CLAVERÍAS, Belén, Consum i condicions de vida a la Catalunya Moderna. El Penedés, 1670-1790Barcelona, 2007 y "Pautas de consumo y diferenciación social en El Penedés a fines del siglo XVII. Una propuesta metodológica a partir de inventarios sin valoraciones monetarias", en Revista de Historia Económica, № extraordinario, Madrid, 2003, pp. 207-245.

45. SANZ YAGÜE, Ana Isabel, "Patrimonio, cultura material y diferenciación social en la ciudad de Soria durante el siglo XVIII", Nuevo Mundo Mundos Nuevos, [En línea], Coloquios, 2008 -consultado el 3 de noviembre de 2018-. URL: http:// journals.openedition.org/nuevomundo/22902.

46. FRANCO RUBIO, Gloria (Ed.), La vida de cada día. Rituales, costumbres y rutinas cotidianas en la España Moderna, Sevilla, 2012.

47. MARURI VILLANUEVA, Ramón, La burguesía mercantil santanderina, 1700-1850 (Cambio social y de mentalidad), Santander, 1990.

48. LICK, Richard, "Les intérieurs domestiques dans la seconde moitié du XVIIle siècle d'après les inventaires après décès de Coutances", en Annales de Normadie, 20, Caen, 1970, pp. 293-315.

49. SHAMMAS, Carole, The Pre-industrial Consumer in England and America, Oxford, 1990. 
Weatherill ${ }^{50}$, Madureira ${ }^{51}$, Ago ${ }^{52}$, Sarti ${ }^{53}$, Roche ${ }^{54}$, Waro-Desjardins ${ }^{55}$ o PardailhéGalabrun ${ }^{56}$. Véanse también los análisis desarrollados por Porres Marijuán ${ }^{57}$ y por Belmonte López, Cuesta Martínez, García Cano y Pozas Poveda ${ }^{58}$. No están de más, también, las propuestas de Fayard ${ }^{59}$, Guerrero Mayllo ${ }^{60}$, Hernández Benítez ${ }^{61}$ y González Heras ${ }^{62}$.

\section{Problemáticas institucionales en el acceso a la mayordomía de Propios}

Los mayordomos de Propios y rentas, al igual que ocurría, entre otros, con los mayordomos del pósito y "Londiga"63, eran propuestos por la "Junta

50. WEATHERIL, Lorna, Consumer Behaviour and material culture in Britain, 1660-1760, Londres-Nueva York, 1988.

51. MADUREIRA, Nuno, Cidade: Espaço e quotidiano (Lisboa, 1740-1830), Lisboa, 1992.

52. AGO, Renata, Il gusto delle cose. Una storia degli oggetti nella Roma del Seicento, Roma, 2006.

53. SARTI, Raffaela, Vida en familia. Casa, comida y vestido en la Europa Moderna, Barcelona, 2002.

54. ROCHE, Daniel, Histoire des choses banales. Naissance de la consommation (XVIleXIXe siècles), París, 1997 y La culture des apparences. Une histoire du vêtement (XVIle-XVIIIe siècles), París, 1989.

55. WARO-DESJARDINS, Françoise, La vie quotidienne dans Le Vexin au XVIIle siècle. Dans l'intimité d'une société rurale, Condé-sur-Noireau, 1992 y "Permanences et mutations de la vie domestique au XVIIle siècle: Un village du Vexin français", en Revue d'histoire moderne et contemporaine, 40, París, 1993, pp. 3-29.

56. PARDAILHE-GALABRUN, Annik, La naissance de l'intime. 3000 foyers parisiens. XVIle-XVIIIe siècles, París, 1988.

57. PORRES MARIJUÁN, Rosario (Dir.), Aproximación metodológica a los protocolos notariales de Álava (Edad Moderna), Bilbao, 1996.

58. BELMONTE LÓPEZ HUICI, Ma Carmen, CUESTA MARTÍNEZ, Manuel, GARCÍA CANO, M ${ }^{a}$ Isabel y POZAS POVEDA, Lázaro, "Las actas capitulares como fuente para la historia urbana", en La Ciudad Hispánica, siglos XIII al XVI, Madrid, 1987, pp. 39-68.

59. FAYARD, Janine, Los miembros del Consejo de Castilla (1621-1746), Madrid, 1982 y "Fortune et hiérarchie au Conseil de Castille aux XVIle et XVIIIe siècles: Les Arce et les Medrano", I Jornadas de Metodología Aplicada de las Ciencias Históricas, Madrid, 1975, volumen 3, pp. 541-550.

60. GUERRERO MAYLLO, Ana, Familia y vida cotidiana de una elite de poder: Ios regidores madrileños en tiempos de Felipe II, Madrid, 1993 y Oligarquía y gobierno municipal en la corte de la monarquía hispánica: el concejo de Madrid entre 1550 y 1606, Madrid, 1991.

61. HERNÁNDEZ BENÍTEZ, Mauro, A la sombra de la Corona: poder y oligarquía urbana (Madrid, 1606-1808), Madrid, 1995.

62. GONZÁLEZ HERAS, Natalia, Servir al rey y vivir en la corte: propiedad, formas de residencia y cultura material en el Madrid borbónico, Madrid, 2014.

63. SANZ de la HIGUERA, Francisco, "Cultura material de los mayordomos del pósito y "Londiga" en el Burgos del Setecientos", Boletín de la Institución Fernán González, 257, 2018, pp. 307-325. 
de República", ya fuera por "Los Procuradores de las Onze colaciones y vecindades" hasta 1768, o, desde ese momento, "por los Doze Comisarios que nombrasen cada uno de los Varrios o Parroquias". En la ciudad de Burgos, la novedosa legislación borbónica se materializaba en la "interbencción de ttodo el vecindario de ella, que esttá dividida en ocho colaziones o Barrios, que comprenden sus Cattorze Parroquias". Se había observado "que subsisttiendo la antterior repca, que solo se componia de Diez y seis Pro[curado] res, que se Ilaman de colaciones en fuerza de Exria expecial y ordenanza con que se rije y govierna estta Ciudad, aprobadas por V. A. con fha de ttres de feb $^{\circ}$ de mil setecienttos quarentta y seis". Empero, se establecía una excepción, la de los "Maiordomos de Propios, que bajo de la misma regla, le elijen los que componen la Juntta de Propios y arvittrios, en fuerza de las Ordenes expedidas por V. A." Así se presumía que esta elección se haría "con más conocimto" y "libre de ttoda parcialidad por los Doze Comisarios que nombrasen anualmente respecttibamte los vecindarios de dhas ocho Colaciones" ${ }^{64}$.

El mayordomo de Propios era, en la práctica, el tesorero del Concejo. Era un empleo de gran importancia económica y una notable influencia en el gobierno municipal. Ofrecía la posibilidad de escalar posiciones desde la perspectiva social, política y económica, de medrar en la vecindad, e incluso fuera de ella -sobre todo, cuando las autoridades de La Corte ponían los ojos en un posible, y útil, peón en los intrincados mecanismos de las redes de influencia de Madrid y las periferias-. En las próximas páginas, se enfatiza como el cargo fue ocupado por hombres del común generalmente acomodados, con excepciones, que buscaban ascender en escala socioeconómica.

Como ocurría en muchas de las capitales españolas del XVIII -Guadalajara, Albacete, Vitoria...-, la administración económica de la hacienda municipal -los bienes de Propios- no estaban directamente en manos de los regidores. La gestión recaía, después del nombramiento del Concejo-siempre atento a su discurrir y a la supervisión posterior de las cuentas- en personas de confianza y capacidad y, por lo general, con recursos económicos suficientes. Sus quehaceres no estaban exentos de algunos riesgos. Para evitar pérdidas en el erario público, y alejar acusaciones de mala gestión, después del nombramiento señalaban unas fianzas. Respondía, a la postre, con sus propios bienes o los de sus avalistas. Lamentablemente, en el Burgos del Setecientos, ya sea en Concejil como en las Actas de gobierno municipal, no se explicitan-como

64. Las citas textuales de este párrafo en AMB. AG. Regimiento del 1 de febrero de 1768, folios 42-43. Véase, a este respecto, CAMPESE GALLEGO, Fernando, Los representantes del Común en el Ayuntamiento de Sevilla (1766-1808), Sevilla, 2005 y SANZ YAGÜE, Ana Isabel, Representación política y participación directa. El "policentrismo" político de Soria y la supervivencia del estado del Común en el siglo XVIII, Madrid, 2018. 
si ocurre con la mayordomía del pósito y "Lóndiga"- las cantidades concretas de los avales. Los mayordomos de Propios, y sus "fiadores Ilanos" aparecen sistemáticamente como "Pagadores, haziendo, Como para ello azemos, de deuda y fecho ageno nro propio, y sin que sea necesario hazer excursión de Vienes ni otra dilizenzia alguna, Aunque de dro se requiera"65. En Guadalajara, por ejemplo -como paradigma modélico de reconstrucción de la economía urbana del XVIII- las fianzas se movían en cifras tan substanciales como 90.000, 225.000 o incluso 239.473 reales $^{66}$. En Vitoria, las responsabilidades no recaían en exclusiva en el mayordomo de Propios sino que, desde 1747, se extendía "a aquellos capitulares que hubieran procedido a su elección y nombramiento" 67 .

Se plantean, a mi juicio, Ilegados a este punto, al menos tres aspectos esenciales en estas circunstancias. En primera instancia, describir si el nombramiento de mayordomo de Propios se efectuaba de una forma regular y sin sobresaltos o se generaban graves problemas de concreción. En segundo término, ¿qué salarios percibieron por sus gestiones al frente de la susodicha mayordomía? Y, a la postre, ¿en qué categorías socio-profesionales estaban instalados dichos individuos? ¿Existe relación entre sus quehaceres laborales como mayordomos de Propios y sus niveles de fortuna?

\section{El devenir del nombramiento}

Por lo que se refiere al protocolo de nombramiento, auscultadas las secuencias de nombramiento y de puesta en escena del nuevo mayordomo de Propios, año tras año, hallamos que el $81,4 \%$ de las ocurrencias -57 años- sucedieron sin ningún tipo de problema. No obstante, en el 18,6\% -13 años- se registran diversos "cortocircuitos" que enturbiaron, de forma dramática, el devenir de la asunción de competencias por los susodichos mayordomos.

Las causas que explican tales circunstancias son múltiples. En 1706, Juan Monedero se negó en rotundo "defendiendose por decir no saber leer ni escribir" 68 . Ese mismo año, a Felipe González se le amenazó con un rotundo "Se le ponga Presso en la carzel Real desta Ciudad en caso de no azeptar" ${ }^{\prime 69}$. No le quedó más opción que colaborar con el Concejo, dado que sus argumentaciones no eran aceptables para los regidores.

65. Véase, por ejemplo, AHPB. Concejil. Juan Francisco García de la Penilla. Legajo 73 (18 de enero de 1735), folios 228-232.

66. SALGADO OLMEDA, Félix, Oligarquía urbana y gobierno..., p. 90.

67. PORRES MARIJUÁN, Rosario, Gobierno y administración de la ciudad..., p. 138.

68. AMB. AG. Regimiento del 2 de enero de 1706, folio 6v.

69. AMB. AG. Regimiento del 1 de febrero de 1706, folio 37r. 
En 1710 y 1739 se esgrimió la incompatibilidad de la mayordomía de Propios con otros empleos. En 1710, por ser uno de los propuestos receptor del papel sellado ${ }^{70}$. Como sucedía en otras localidades, por ejemplo en Santiago de Compostela, la norma común era que "No se les permitía desempeñar otro puesto en el municipio"71.

La pobreza fue la eximente esgrimido en 1712. Manuel Varona suplicó a la Ciudad "que en atención a hallarse sumamente Pobre, tanto que a no balerse de algunas comisiones hera ymposible Poder alimenttarse y a su dilattada familia (...) [y] teniendo presente tan fastos motivos [pide] darle por libre por uno de los propuestos para Maymo de propios"72. En 1727, la situación se dislocó, hasta el paroxismo, por múltiples motivos ${ }^{73}$ y $1738^{74}$. Un requisito esencial, también universal en otras ciudades, era que "gozase de una determinada fortuna para poder responder de los posibles descubiertos en el ejercicio del cargo" ${ }^{\prime 75}$.

Una queja utilizada para rechazar la mayordomía era, en efecto, "hallarse con número Crezido de hijos y con Cortos Medios para la manutención..."76. En 1720, el Concejo solicitó otras propuestas. Exigía que era imprescindible para decir el nombramiento que dichas personas serían nombradas "teniendoles por haviles"77. En la segunda terna de 1720, el Consejo rechazó la candidatura de Pedro Tomé González, tendero, quien Ilegaría a ejercer como uno de los personajes más sobresalientes de Burgos en el XVIII. En 1709 sucedió

70. AMB. AG. Regimiento del 12 de enero de 1710, folio 12r. El Concejo esgrimía, a su vez, "no ser sujetos a propósito los propuestos para semejante empleo". Exigió "se le haga saber a las Vecindades para que propongan otro en su lugar", folio 7r. En 1739, uno de los propuestos como mayordomo lo había sido también como fiel municipal. AMB. AG. Regimiento del 2 de enero de 1739, folio $7 \mathrm{v}$.

71. CEBREIROS ÁLVAREZ, Eduardo, El municipio de Santiago de Compostela..., p. 178.

72. AMB. AG. Regimiento del 2 de enero de 1712, folio 4-5.

73. Es muy probable que tales circunstancias sucedieran todos los años, si bien únicamente tenemos constancia de ello en 1728. El Concejo reconocía la existencia de problema, "mediante los muchos que an sido propuestos para dho empleo". Tres no sabían ni leer ni escribir, dos tenían muchos hijos, otros dos sufrían severas enfermedades, dos más estaban recién casados y uno estaba inhabilitado como consecuencia de sus actividades profesionales. AMB. AG. Regimiento del 21 de junio de 1727, folio 157.

74. Felipe Linares indicó, de manera reiterada, en sus memoriales al Concejo que no sabía ni leer ni escribir, que daba prioridad absoluta a su trabajo como calderero y latonero, que tenía muchas ocupaciones y, en última instancia "hallarse con cortísimos medios y con total imposibilidad de anticipar mrs algunos". AMB. AG. Regimiento del 21 de junio de 1727, folio 157 y Regimiento del 27 de febrero de 1728, folio 78v.

75. Véase CEBREIROS ÁlVAREZ, Eduardo, El municipio de Santiago de Compostela..., p. 177.

76. A ella recurrió, por ejemplo, Andrés Díez de Leiva en AMB. AG. Regimiento del 11 de enero de 1714 , folio $24 \mathrm{v}$.

77. AMB. AG. Regimiento del 2 de enero de 1720, folio $6 r$. 
lo mismo $^{78}$. En 1744, uno de los seleccionados "se defiende en Justicia para que se le de por libre de dha propuesta por sus achaques y abanzada edad"79. En 1760, Bernabé Izquierdo pidió reiteradamente ser exonerado y retrasó, al máximo, definir las fianzas ${ }^{80}$. En 1761, a la postre, el Concejo "resolvio el suspender, como suspendieron, el nombrar Maiordomo de propios (...) para este año, mediante lo prevenido por el Real Decretto e Instrucción expedida por SM (...) en treinta de julio deel año próximo pasado para la Mejor Administración de los Propios y Arbitrios". Se nombró mayordomo "interino" a la espera de los acontecimientos ${ }^{81}$.

El mayordomo de propios en la ciudad de Burgos era elegido de manera anual, aunque después, en la práctica, se produjeron repeticiones puntuales. Ello sucede igualmente en Santiago de Compostela ${ }^{82}$ o en Vitoria ${ }^{83}$. Sin embargo, en Valencia "tenía carácter vitalicio"84. En Burgos el 70\% de los mayordomos sólo lo fueron un año, sin más. El $12.5 \%$ en cinco ocasiones. El $7.5 \%$ en tres, el $2.5 \%$ en 4 y 5 , respectivamente. Que el mayordomo de propios lo fuera en siete años consecutivos únicamente ocurrió en dos períodos. Se trata, en primera instancia, de 1723 y 1727-1732, fenómeno protagonizado por el comerciante de paños Francisco Izquierdo González. En segundo término, por Francisco Castrillo Castañeda (1744-1750). En ambos casos, como respuesta a graves deterioros del proceso de nombramiento, como se ha señalado anteriormente.

\section{El salario del mayordomo de Propios}

La gratificación municipal, computada "Al Mayordomo de propios" entre los "Salarios de ministros Y criados de la ciudad"85 (véase Gráfico 2), convertía al individuo nombrado en un "funcionario" circunstancial del Ayuntamiento

78. AMB. AG. Regimiento del 8 de enero de 1720, folio 13r y Regimiento del 2 de enero de 1709, folio 15 r.

79. AMB. AG. Regimiento del 2 de enero de 1744, folio 3r. Acabó siendo nombrado Francisco Castillo Castañeda, por seis años (1744-1750). AMB. AG. Regimiento del 11 de enero de 1744, folios 19v-20r.

80. AMB. AG. Regimiento del 2 de enero de 1760, folio 3r; Regimiento del 10 de enero de 1760, folio 21r; Regimiento del 21 de enero de 1760, folio 30r y Regimiento del 21 de julio de 1760, folio $219 \mathrm{v}$.

81. AMB. AG. Regimiento del 8 de enero de 1761, folio $24-25$ y 22 de enero de 1761, folio 67 r. 176.

82. CEBREIROS ÁlVAREZ, Eduardo, El municipio de Santiago de Compostela..., pp. 174-

83. PORRES MARIJUÁN, Rosario, Gobierno y administración de la ciudad..., p. 138.

84. HERNANDO SERRA, Ma Pilar, "Un siglo de reformas: Haciendas municipales y Reglamentos en la Valencia del XVIII", AHDE, 83, 2013, p. 550.

85. Véase AMB. AG. 1700-1771, en los Regimientos celebrados el 2 de enero de cada año. 
(Concejo), al menos por un año. Con objeto de estimular la aceptación de tales responsabilidades, los salarios, fijos, se fueron incrementando gradualmente hasta 1750. En 1700-1713 suponía 941 reales; en 1714-1733, 1.430 reales de vellón y en 1744-1749 150 ducados (1.650 reales). En 1750-1759 decae hasta los 1.100 reales y, a la postre, a partir de 1760 se le adjudican "Quince al millar" 86 . En Santiago de Compostela el mayordomo de propios "cobraba un salario hijo todos los años de 3.000 reales $^{\prime \prime 87}$. En Murcia 200 reales anuales $^{88}$. En Vitoria, el "bolsero" -o mayordomo de propios ${ }^{89}$ - percibía 117 reales y 22 maravedíes -más 50 ducados de la bolsa de la Sisa, en concepto de tesorero de la misma- ${ }^{90}$. En Albacete el salario fijo era casi similar, 60 ducados, pero "superior -enfatiza Cózar Gutiérrez- a los 50 ducados que cobraban en Guadalajara"91, a los 400 reales de Tarazona de La Mancha ${ }^{92}$ y, por supuesto, a los 294 reales/año de Soria ${ }^{93}$. Nada que ver con los 2.200 reales que percibía en Córdoba ${ }^{94}$ y los 600 ducados de Granada ${ }^{95}$. En el puzzle territorial español, la característica más usual era el sorprendente grado de disparidad que podía percibir un mayordomo de propios en lo tocante a su salario fijo anual. Burgos se sitúa en un término intermedio, entre lo raquítico de Vitoria, Albacete o Guadalajara y la enormidad de Santiago de Compostela o de Granada. Las retribuciones anuales eran un poderoso atractivo para la asunción de esas responsabilidades y alimentaban sus niveles de renta y de fortuna.

86. Sobre esta fórmula véase CEBREIROS ÁlVAREZ, Eduardo, El municipio de Santiago de Compostela..., p. 183.

87. Según el Catastro de Ensenada, percibía, en 1752, 4.400 reales. Véase CEBREIROS ÁlVAREZ, Eduardo, El municipio de Santiago de Compostela..., p. 183.

88. BERMÚDEZ AZNAR, Agustín, "El reformismo institucional ilustrado en el reino de Murcia durante el siglo XVIII", en Historia de la Región murciana, vol. VII, Murcia, 1984 , p. 97.

89. Llamado en Cataluña y en Valencia "Clavario" -véase GARCÍA GARCÍA, Carmen, "Haciendas municipales y bienes de propios: Las reforma de Carlos III", Anales de estudios económicos y empresariales, 1, 1986, pp. 89-114- y "depositario" en León, Zamora y Salamanca -véase GÓMEZ MARTíNEZ, Alfredo, "Cargos y oficios municipales en las ciudades de León, Zamora y Salamanca durante el reinado de Carlos III", Estudios Humanísticos, 5, 2006, pp. 159-184-.

90. PORRES MARIJUÁN, Ma Rosario, Gobierno y administración de la ciudad de Vitoria en la primera mitad del siglo XVIII, p. 139.

91. CÓZZAR GUTIÉRREZ, Ramón, Gobierno municipal y oligarquías. Los oficios públicos de la villa de Albacete en el siglo XVIII, Cuenca, 2008, p. 998.

92. Archivo Histórico Provincial de Albacete. Catastro de Ensenada. Respuestas Generales. Caja 176. Tomado de CÓZAR GUTIÉRREZ, p. 998.

93. SANZ YAGÜE, Ana Isabel, La ciudad de Soria en el siglo XVIII. Un estudio sociocultural, Soria, 2012, p. 1328.

94. CUESTA MARTíNEZ, Manuel, Oficios públicos y sociedad. Administración urbana y relaciones de poder en la Córdoba de finales del Antiguo Régimen, Córdoba, 1997, p. 106.

95. MARINA BARBA, Jesús, Poder municipal y reforma en Granada durante el siglo XVIII, Granada, 1992, p. 230. 


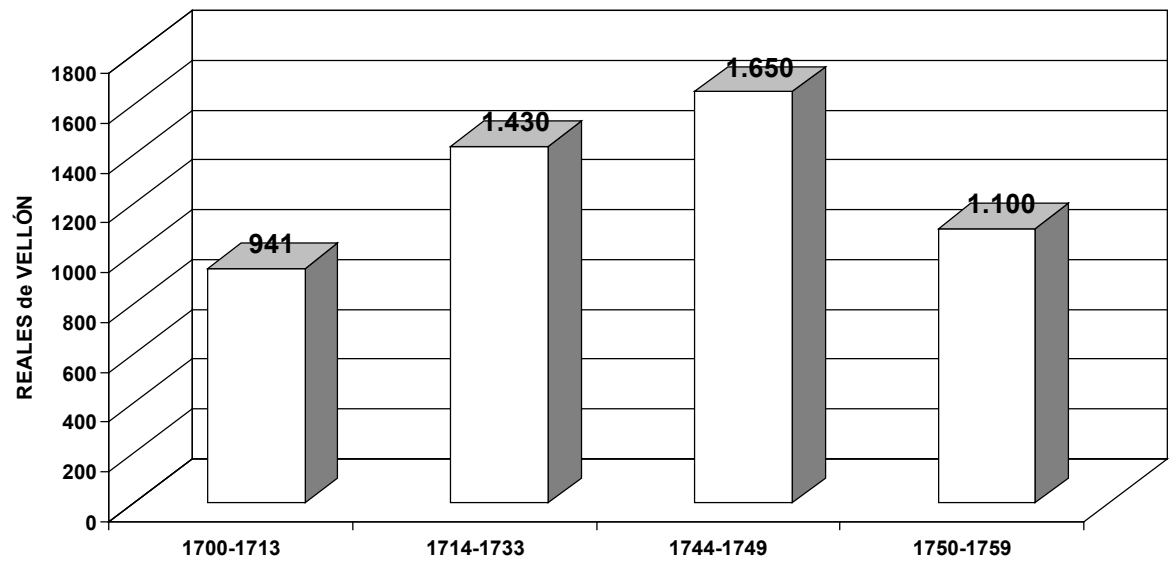

GráfICO 2. Salario del mayordomo de propios en Burgos.

\section{Nivel de fortuna de los mayordomos de Propios en el Burgos del Setecientos}

Fuera o no accidentado el acceso a la mayordomía de Propios, en el Burgos del Setecientos no todos los que alcanzaron ese empleo gozaban de un nivel de fortuna, ni disponían de una cultura material, de similar calibre (véase Gráfico 3). Obviamente, van a ser mencionados únicamente aquellos para los cuales disponemos de inventarios de bienes, es decir, como sabemos, 17 (41.5\%) de los 41 individuos que ejercieron la mayordomía en 1702-1771. El promedio de aquellos para quienes se ha podido recopilar sus niveles de fortuna, de promedio 100.102 reales, casi duplican el promedio global de la ciudad de Burgos en el XVIII, 54.787 reales $^{96}$.

En 1703 fue nombrado un labrador, pechero, Agustín Pérez Gallo, que disponía, al fallecer, en 1716, de unos escuetos 9.977 reales de vellón ${ }^{97}$. Probablemente, los 941 reales del salario por ser mayordomo en esa época serían un regalo a su modesta economía. Y más si tenemos en cuenta que el promedio de los labradores de Burgos en el XVIII era de 13.134 reales, es decir, bastante mayor que el disponible por el citado Agustín. La propuesta de los procuradores

96. En todas las menciones a categorías socio-profesionales, se efectúa un contraste entre el nivel de fortuna que disponían los mayordomos de propios con relación al del total de los inventarios de bienes disponibles para su categoría.

97. AHPB. PN. Santiago Romo. Legajo 6978 (11 de febrero de 1729), folios 613-627. 
y el nombramiento por parte de los regidores a un labrador modesto constituye un acontecimiento memorable, y no repetido.

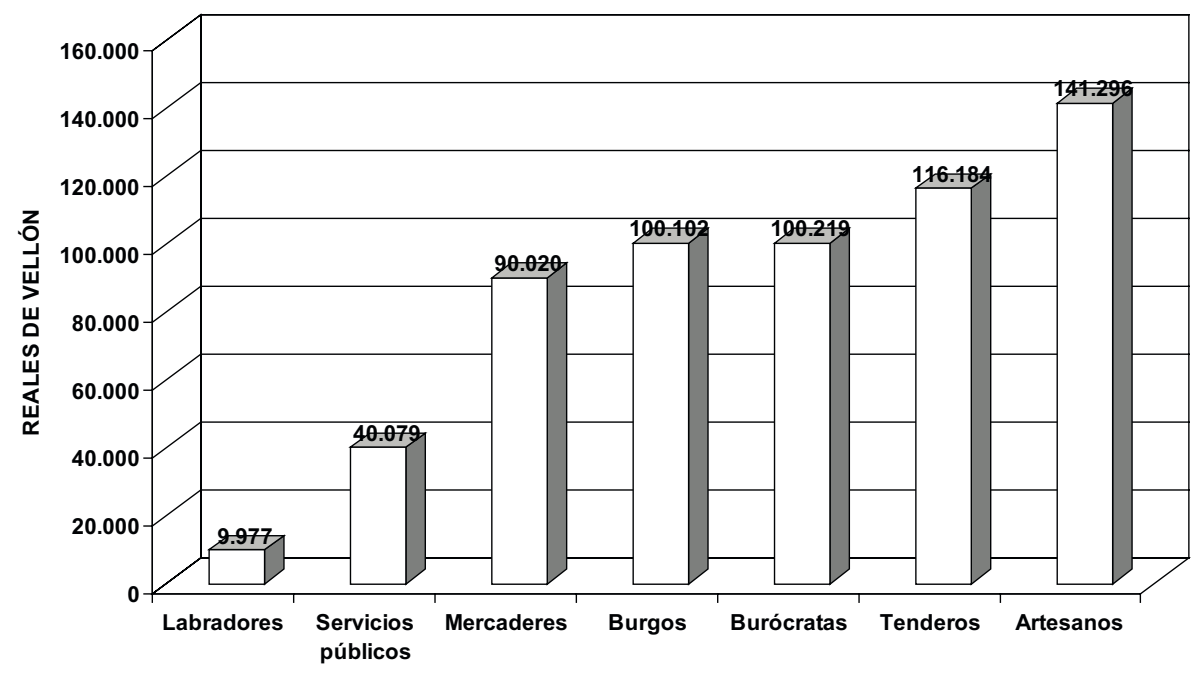

GráfICO 3. Nivel de fortuna de los mayordomos de propios.

En 1722, por su parte, fue nombrado Agustín Sevilla, un calesero y cochero, también pechero del estado general ${ }^{98}$. En el momento de su óbito gozaba de un patrimonio bastante más apreciable, 40.079 1/2 reales. Los 1.430 reales del salario como mayordomo no eran una bagatela. Este otro Agustín duplicaba el promedio de sus "compadres" de categoría socio-profesional, 20.137 reales. Con estos dos apuntes, resulta aceptable asumir, y vale también para los demás mayordomos recopilados, que "La costumbre de ser mayordomo [de Propios] no estuvo condicionada -señala Sanz Yagüe- por el orden social, de modo que la asumieron tanto los vecinos del estado general como la nobleza" ${ }^{\prime \prime 9}$.

Los comerciantes de paños, ambos hijodalgos, adquirieron esa condición en dos ocasiones. Su promedio, 90.020 reales, es muy inferior al de dicha categoría socio-profesional en el Setecientos, 247.774 reales. Los mercader al por mayor propietarios de niveles de fortuna de mucho mayor relieve patrimonial accedieron a otras mayordomías quizá más apetecibles, como, por ejemplo, la

98. AHPB. PN. Diego Fernández Cormenzana. Legajo 7074 (26 de marzo de 1735), folios 373-388.

99. SANZ YAGÜE, Ana Isabel, La ciudad de Soria en el sig/o XVIII ..., pp. 1-041. 
mayordomía del pósito y "Lóndiga"100. Evidentemente, los salarios percibidos, fueran 1.430 o 1.100 reales, no eran un aliciente para estos quehaceres. Forzado o no el desempeño de dicho empleo por las circunstancias, la mayordomía de Propios era una ocasión magnífica para potenciar su presencia en la economía de la ciudad y más allá. En 1723 y 1727-1732 le tocó el turno, tras un año previo accidentado, a Francisco Izquierdo González, quien al morir disponía de un nivel de fortuna significativo, 124.929 1/2 reales ${ }^{101}$. El otro es Manuel Sáinz de Viniegra, mayordomo de Propios en 1766-1767. Al fallecer, gozaba de 55.112 reales, cantidad que era sensiblemente inferior a la que tuvo en los momentos de su máximo nivel de fortuna, antes de la desgraciada intervención en la tahona de pan de Burgos. A mi juicio, antes de la quiebra de ese adverso proceso empresarial, Manuel Sáinz de Viniegra disfrutaba de un patrimonio aproximado de 250.000 reales $-^{102}$.

De los burócratas que accedieron, en un momento u otro, a la mayordomía de Propios obtenemos un promedio patrimonial de 100.210 reales, similar al promedio de toda esa categoría socio-profesional en el Burgos del Setecientos, 103.570 reales. El $50 \%$ eran nobles y un $25 \%$, respectivamente, hidalgos y del estamento general, pechero. En 1702 el propuesto y nombrado fue un profesional de Hacienda, cajero principal de rentas, noble, Jerónimo San Martín, dotado al morir de un paupérrimo nivel de fortuna, 8.270 reales $^{103}$. En 1714-1715, Francisco López de Séneca, hidalgo, escribano del número, asumió esos quehaceres. De su óbito se extrae que su nivel de fortuna no era monumental, dado que disponía de bienes libres evaluados en 37.334 1/2 reales $^{104}$. Pedro Sanz de Sautuola atesoraba un patrimonio similar, 37.809. Era noble y desempeñaba sus labores profesionales en la Administración General de las Rentas como cajero del servicio de millones ${ }^{105}$. El más afortunado, y con mejor nivel de vida y fortuna, fue el cajero de sisas en

100. SANZ de la HIGUERA, Francisco, "Cultura material de los mayordomos del pósito y "Londiga" en el Burgos del Setecientos", Boletín de la Institución Fernán González, 257, 2018, pp. 307-325. Descuellan, en especial, el mercader de paños y sedas Francisco Sáinz de Viniegra, mayordomo del pósito en 1731-1738, poseedor de un patrimonio de 524.813 reales -AHPB. PN. Francisco Villafranca. Legajo 7098/1 (16 de diciembre de 1768), folios 1-50- y el también mercader de paños y sedas Agustín del Castillo (mayordomo del pósito en1762-1764), con un nivel de fortuna evaluado en 295.403 reales -AHPB. PN. Francisco Sanz Escolar. Legajo 7237, 30 de noviembre de 1791, sin foliar-.

101. AHPB. PN. Domingo Hontoria. Legajo 7195/1 (15 de julio de 1767), sin foliar.

102. AHPB. Justicia Municipal. Alonso Melo Peña. Legajo 983 (1 de julio de 1786), folios 2-17. Es una mera hipótesis que encaja, sin estridencias, con el promedio de los comerciantes de paños de Burgos en el devenir del Setecientos.

103. AHPB. PN. José Fernández Guilarte. Legajo 6907 (14 de noviembre de 1716), folios 514-523.

104. AHPB. PN. Santiago Romo. Legajo 6979 (15 de abril de 1733), folios 593-616.

105. AHPB. PN. Juan Antonio Fernández Guilarte. Legajo 7008 (23 de julio de 1741), folios 497-514. 
dicha Administración Francisco Castillo Castañeda. A pesar de su substancial patrimonio libre -317.465 reales-, era pechero. Asumió la mayordomía de Propios después de un par de años difíciles en lo tocante al nombramiento de ese empleo (1742-1743). Estuvo al frente de la susodicha mayordomía en 1744-1750, "por seis años"106, superando a Jacinto Delgado (1737-1741).

Los mercader al por menor, los tenderos, estaban repartidos de una forma más o menos equilibrada entre el estado general, $37.5 \%$, y el estado nobiliar -el 37.5 $\%$ eran hidalgos y el $25 \%$ nobles de sangre-. Su presencia al frente de la mayordomía de Propios se materializa en la aparición de individuos con niveles de fortuna generalmente elevados, aunque hay excepciones -el promedio de los recopilados sobrepasa los 116.000 reales, cantidad significativa porque el promedio de los tenderos del XVIII burgalés en su conjunto era prácticamente la mitad, 54.793 reales-. En 1705, Francisco Gandía Alcalde, mercader de cerería, pechero, accede a la mayordomía de Propios. Al fallecer, en 1726, disponía de 37.682 reales ${ }^{107}$. Bastante menos afortunado, el también tendero Gaspar Martínez Torres, pechero, fue mayordomo de Propios en 1716-1717 y su nivel de fortuna, en 1720, a la hora de su óbito, era de poco más de 4.000 reales $^{108}$. Manuel Cortés de Rueda, mercader de joyería, hidalgo, dirigió los Propios en 1734 y, al fallecer, su patrimonio acumulaba bienes computados en 118.480 reales $^{109}$. Lesmes López de Séneca, mercader de cerería, noble, gestionó los Propios en 1735 y su nivel de fortuna, al hilo de su óbito, se tasó en 48.185 reales $^{110}$. En 1751, el mayordomo de Propios fue el tendero de joyería, de extracción noble, José Gómez de Velasco. Falleció en 1754 con un patrimonio importante -92.408 reales de vellón- ${ }^{111}$. En 1756-1758, el mayordomo de Propios fue el hidalgo mercader de joyería Santiago Gutiérrez Marañón. Su nivel de fortuna fue evaluado en 166.285 1/2 reales en $1784^{112}$. Bernabé Izquierdo, pechero, tendero, fue responsable de los Propios en 1760. Su nivel de fortuna, computado en 1766, se elevó a $283.2341 \frac{1}{2}$ reales $^{113}$. Diego Puente Morales, tendero, hidalgo, fue mayordomo de Propios en 1762-1764. Dispuso de un patrimonio notable, 179.112 $1 / 2$ reales $^{114}$.

106. Archivo Municipal de Burgos. Alonso Melo Peña. Legajo HI-5104 (30 de diciembre de 1757), sin foliar.

107. AHPB. PN. Juan Francisco García Penilla. Legajo 6985/2 (25 de octubre de 1726), folios 190-211. También fue mayordomo del pósito en 1719-1723.

108. AHPB. PN. Francisco Vitoria. Legajo 6951/1 (5 de enero de 1720), folios 680-695.

109. AHPB. PN. Francisco Villafranca. Legajo 7093 (22 de diciembre de 1757), folios 257300. Fue también mayordomo de la alhóndiga en 1739-1741.

110. AHPB. PN. Diego Fernández Cormenzana. Legajo 7081 (11 de noviembre de 1750), folios 345-359.

111. AHPB. PN. Manuel Silvestre Iturriaga. Legajo 7144/2 (15 de enero de 1754), folios 252-289.

112. AHPN. PN. Alonso Melo Peña. Legajo 7219 (23 de mayo de 1784), folios 194-201.

113. AHPB. PN. Nicolás Martínez Vivanco. Legajo 7149 (25 de febrero de 1766), folios 311-468.

114. AHPB. PN. Bernardo Alonso Illera. Legajo 7189 (22 de noviembre de 1766), folios 790-823. Mayordomo del pósito en 1765-1768. 
Algunos de los mayordomos de Propios para quienes no disponemos de inventario de bienes, generalmente post-mortem, nos consta que también fueron mercaderes al por menor. Juan López de Cotar (1726) fue mercader con confitería. Ventura de la Puente (1736), igualmente mercader de confitería y obligado de la carbonería. Jacinto Delgado (1737-1741), mercader de chocolate. Miguel Pérez Arroyo (1742 y 1752-1754), mercader de cerería y de confitería. Es significativo, a mi entender, que, por ejemplo, Pedro Tomé González, hidalgo y mercader de joyería, fue propuesto en 1709 y 1720 . Nunca consiguió ser nombrado por el Concejo como mayordomo de Propios. Tampoco le hizo falta. Llegó, con el tiempo y con el despliegue de sus múltiples quehaceres "empresariales", a ser, sin duda, uno de los individuos más ricos del Burgos en el Setecientos ${ }^{115}$. Si hubiéramos dispuesto de sus niveles de fortuna, se contemplaría un panorama mucho más intenso en lo tocante a la participación de los mercaderes al por menor en la gestión de la mayordomía de Propios. De hecho, Pedro Tomé González en 1703 disponía de un nivel de fortuna evaluado, en el momento de sus primeras nupcias, en 21.440 1/2 reales ${ }^{116}$. En 1724, al hilo del óbito de su cónyuge, había alcanzado una cifra sorprendente, 339.048 1/2 reales $^{117}$. Falleció en 1764 con 1.509 .477 reales en bienes libres ${ }^{118}$. En 1765, la mayordomía de Propios recayó en José Astúlez, un mercader de joyería e impresor que falleció, en 1783 con un patrimonio evaluado en 641.089 1/2 reales $^{119}$.

Un análisis crítico de quienes asumieron, en el Burgos del XVIII (1702-1771), la mayordomía de Propios posibilita evaluar su extracción estamental, sus actividades económicas, sus estrategias familiares y clientelares y sus posibilidades de ascenso socio-económico. En sus cabezas, en sus estrategias de futuro, albergaban "comportamientos emulatorios a los de la oligarquía urbana (...) [puesto que] en definitiva, la gestión de los ingresos y gastos del concejo, su cercanía al poder y a una fuente financiera de importancia les supuso importantes beneficios en el ámbito social, político y económico"120.

115. Véanse, entre otras, SANZ de la HIGUERA, Francisco, "La cultura material de los tesoreros generales de la Santa Cruzada en el Burgos del XVIII", Cuadernos de estudios del siglo XVIII, 25, 2015, pp. 317-336, "Los mayordomos de la Mesa Capitular de la Catedral de Burgos en el Setecientos (1707-1782)", Trocadero, 25, 2013, pp. 117-146, "Un esperpéntico asuntillo de Estado: La casa de los Tomé en el Setecientos burgalés", Cuadernos de estudios del siglo XVIII, 21, 2011, pp. 287-318 y "Las "restauraciones" del Consulado de Burgos en el siglo XVIII", Historia, Instituciones, Documentos, 29, 2002, pp. 429-458.

116. AHPB. PN. José Mata. Legajo 6917 (11 de enero de 1703), folios 218-229.

117. AHPB. PN. Martín Robredo. Legajo 6964 (14 de enero de 1724), folios 340-353.

118. AHPB. Justicia Municipal. Juan Antonio Fernández Guilarte. Legajo 977 (14 de julio de 1764), folios 21-127.

119. Archivo Municipal de Burgos. Rafael Martín. Legajo HI-5058 (1805), sin foliar.

120. CASTILLO FERNÁNDEZ, Javier, "Negocios de familia': El perfil institucional y social de los mayordomos de propios del reino de Granada (1492-1550)", Crónica Nova, 31, 2005, p. 25. 
En última instancia, sobresale, en lo tocante a su nivel de fortuna y su precocidad, el maestro curtidor y tanador, hidalgo, Felipe González, mayordomo de Propios en 1706 y titular de un patrimonio muy sobresaliente, con 141.296 1/2 reales $^{121}$-el promedio de los artesanos en el Burgos del Setecientos no sobrepasaba los 20.000 reales- en concreto, era de 19.068 reales-.

Lo que destila, para Burgos y para otras localidades de contraste, es que quienes ostentaron los quehaceres de la mayordomía de Propios en la España del Setecientos podían ser calificados -traigo a colación los análisis de Salgado Olmeda, que comparto en su totalidad- "como un grupo de pequeña burguesía, comerciantes y lonjistas, cuya fortuna se basaba en el comercio, la especulación y en la administración de otras rentas, además de las municipales"122. El leitmotiv que se escondía, o ni siquiera eso, en su interés por adquirir el control de ese "empleo" era "el disponer de dinero efectivo -Salgado Olmeda dixit y lo corroboro- (bastante difícil en la época si no se recurría a un censo) que les permitiera utilizarlo en sus lonjas y negocios particulares"123. También es evidente el grado de impacto que su visibilidad pública, como mayordomos de Propios, imprimía a su prestigio como gestores del Común y la posibilidad de codearse con la aristocracia urbana, con los ojos puestos en ascender en el escalafón de mayordomía u otros empleos de interés.

Lo ocurrido en Guadalajara o en Burgos tiene igualmente en Albacete un testigo de contraste. Cózar Gutiérrez, señala la presencia en la mayordomía de Propios de personajes que "pertenecen al grupo medio-alto de la población, pues debían tener un buen patrimonio personal [en Burgos se ha constado rotundamente, salvo excepciones puntuales], así como experiencia en la administración económica para ejercer correctamente esta ocupación. En su mayoría se va a tratar de personajes cuya fortuna se basa en la especulación, el comercio o la administración de otras rentas, que les permitieron amasar rápidamente grandes cantidades de dinero" ${ }^{\prime 24}$.

En resumen, y en ello coinciden las apreciaciones esgrimidas para Guadalajara, Albacete, Granada o Burgos, "La extracción social de estos individuos les sitúa en familias de burócratas, comerciantes o rentistas con buenos ingresos [nivel de rentas] y con importantes patrimonios urbanos [nivel de fortuna]. De hecho los capitulares [regidores perpetuos] tenían muy presente que este oficio, como el de la depositaría general, debía recaer en las personas más acaudala-

121. AHPB. PN. Lázaro Santamaría. Legajo 6870 (9 de abril de 1715), folios 155-190.

122. SALGADO OLMEDA, Félix, Oligarquía urbana y gobierno de la ciudad de Guadalajara en el siglo XVIII (1718-1788), Madrid, 2000, p. 90.

123. SALGADO OLMEDA, Félix, Oligarquía urbana y gobierno de la ciudad de Guadalajara en el siglo XVIII..., p. 92.

124. CÓZAR GUTIÉRREZ, Ramón, Gobierno municipal y oligarquías. Los oficios públicos de la villa de Albacete en el siglo XVIII, Cuenca, 2008, p. 998. 
das de la villa"125. En el Burgos del XVIII, la presencia de profesionales de los servicios públicos, de labradores y de artesanos, junto con comerciantes al por mayor y al por menor y de algunos burócratas, en especial de un segmento tan sensible como la Administración General de Rentas, léase Hacienda, saca a relucir tendencias muy similares a las barajadas para otras ciudades pero con peculiaridades y matizaciones muy particulares.

El contraste entre los niveles de fortuna de aquellos que se ocuparon de las dos mayordomías públicas urbanas, la del pósito, por una parte, y la de los Propios y rentas, por otra, nos ofrece claves diagnósticas para dibujar un panorama, inédito, que tiene mucho de reconstrucción histórica impactante (véase Gráfico 4). En primera instancia, la presencia entre los mayordomos de Propios de un labrador, circunstancia que no existe en los del pósito. Ocurre lo mismo con los burócratas -al menos, en aquellos casos en los que disponemos de su nivel de fortuna-. En el extremo contrario, la mayordomía del pósito ocupada por Jerónimo de la Infanta nos plantea la aparición de un noble rentista, de reducidos caudales -en el entorno de los 100.000 reales-, pero noble al fin ${ }^{126}$.

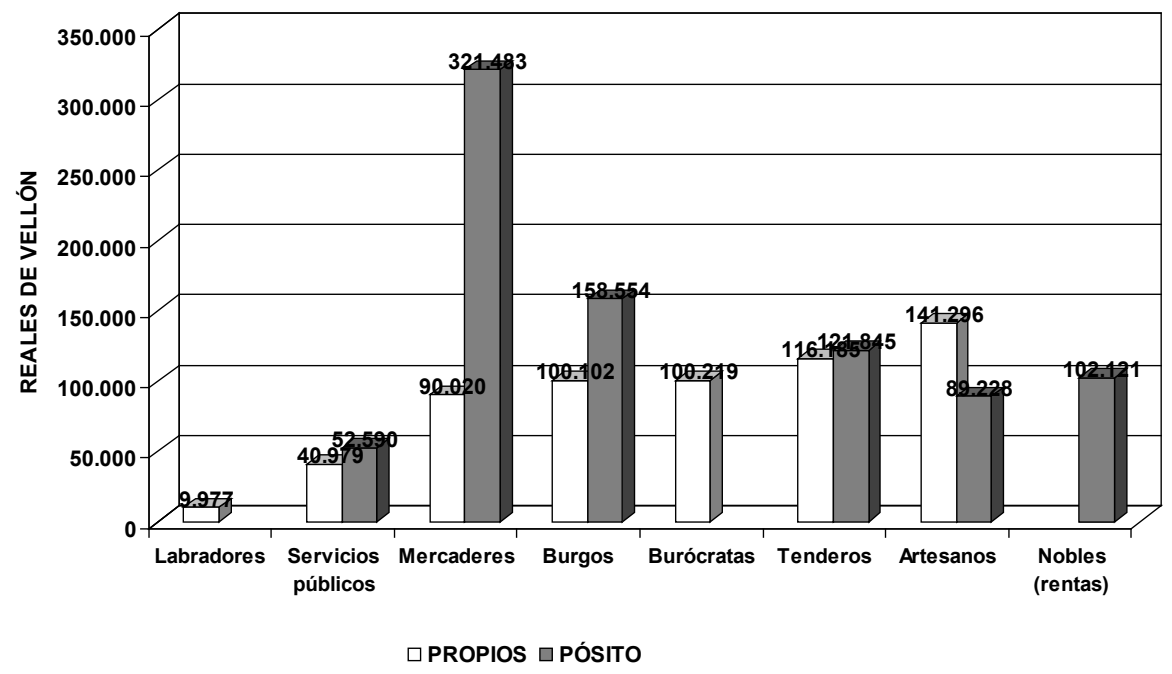

GRÁFICO 4. Nivel de fortuna de mayordomos.

125. CÓZAR GUTIÉRREZ, Ramón, Gobierno municipal y oligarquías. Los oficios públicos de la villa de Albacete en el siglo XVIII, p. 999.

126. SANZ de la HIGUERA, Francisco, "Cultura material de los mayordomos del pósito y "Londiga" en el Burgos del Setecientos", Boletín de la Institución Fernán González, 257, 2018, pp. 307-325. 
En segundo término, el descubrimiento de un cierto equilibrio en sus niveles de fortuna entre los mayordomos de Propios y los del pósito para los profesionales de los servicios públicos y entre los tenderos. En tercer lugar, la constatación de un mejor nivel de fortuna entre los maestros artesanos implicados en la gestión de los Propios que los nombrados para la alhóndiga. En última instancia, se percibe lo contrario para los comerciantes de paños y sedas, los mercaderes al por mayor. La desproporción es tan substancial, 90.020 reales en el caso de los mayordomos de Propios y 321.483 reales para los mayordomos del pósito, que es plausible afirmar que los lonjistas se inclinaban con mayor agrado hacia los quehaceres del pósito que hacia la tesorería de los Propios. El grado de previsibles beneficios y la minimización de los riesgos, el impacto urbano de su labor como mayordomos -con la cultura de las apariencias siempre presente-, la presumible dinamización de las redes de influencia tanto en la ciudad en que residían como en Madrid y el constante manejo de dinero, y de granos, etcétera. Todas ellas constituyen excusas creíbles que encajan sin estridencias en sus estrategias mercantiles y clientelares. Cada jornada es un buen día para ser un poco más acaudalado. Incluso aunque contemplemos, como señala Salgado Olmeda, que "el empleo, la mayoría de las veces, resultaba dudosamente beneficioso"127. Es evidente que ello podría ocurrir de forma más habitual con los Propios, siempre al borde del déficit, o literalmente números rojos en muchos de los ejer$\operatorname{cicios}^{128}$. En la mayordomía de la alhóndiga raramente pasaba ese peligro. En todo caso, en ambas mayordomías, "Los alcances negativos eran pagados de sus patrimonios personales"129, condición que forzosamente era admitida en cada "Escritura para la Mayordomía". Era preciso esmerarse para no cometer errores y gestionar con pulcritud y beneficio el empleo encomendado por las colaciones y el Concejo.

127. SALGADO OLMEDA, Félix, Oligarquía urbana y gobierno de la ciudad de Guadalajara en el siglo XVIII..., p. 92.

128. Véanse, entre otras muchas propuestas de análisis, GUTIÉRREZ ALONSO, Adriano, "La hacienda municipal de Burgos en la época Moderna. Los bienes de Propios (15001750)", Boletín de la Institución Fernán González, 215, 1997, pp. 327-354; GARCÍA GARCÍA, Carmen, La crisis de las haciendas locales: de la reforma administrativa a la reforma fiscal (1743-1845), Valladolid, 1996; TORRES SÁNCHEZ, Rafael, "Hacia un irremediable endeudamiento. La hacienda municipal de Cartagena durante el siglo XVIII" y RUBIO PÉREZ, Laureano, "Haciendas concejiles y haciendas municipales en la provincia de León durante la Edad Moderna", ambas en PEREIRA IGLESIAS, José Luís, BERNARDO ARES, José Manuel y GONZÁLEZ BELTRÁN, José Manuel (Coords.), La administración municipal en la Edad Moderna, V Reunión Científica de la Asociación Española de Historia Moderna, Cádiz, 1999, tomo II, p. 289-307.

129. SALGADO OLMEDA, Félix, Oligarquía urbana y gobierno de la ciudad de Guadalajara en el siglo XVIII..., p. 92, 


\section{A modo de conclusión}

Los Concejos, y dentro de ellos los corregidores, los alcaldes mayores y los regidores perpetuos, declinaban la administración directa, y diaria, de sus Propios y del sistema de préstamo de granos, del pósito y alhóndiga, en vecinos que eran propuestos desde las colaciones y, a la postre, nombrados en los "Regimientos" semanales del Ayuntamiento -cada año, después, darían "Quentas" de sus gestiones, como se comprueba a través de las Actas de gobierno y de los legajos correspondientes del Archivo Municipal de Burgos-. La "maquinaria" de participación directa de la población en la proposición de candidatos se nos escapa en gran parte. Sólo sabemos, en la práctica, de las candidaturas elevadas, año tras año, desde la "Junta de República" con el concurso de "Los Procuradores de las Onze Colaciones y Vecindades". De la reunión efectuada en la sacristía de la parroquia de Santiago de la Capilla -momento que contaba con la asistencia "de otras muchas personas y Vezinos"- devenía la terna en la cual el Concejo debía nombrar uno de los dos para mayordomo, de Propios o de pósito, según el caso. La cuestión de qué se valoraba en los individuos propuestos o cómo se presionaba para llegar a cada etapa del "camino" son cuestiones esenciales que estos momentos aún no están resueltas. Será abordado en próximos trabajos.

Los mayordomos nombrados por el Concejo procedían de múltiples categorías socio-profesionales, aunque nunca nos toparemos con mujeres, jornaleros, pobres de solemnidad, clérigos, militares... Veremos protagonizando las mayordomías a algún que otro labrador, artesano, burócrata modesto, profesional de los servicios públicos -taberneros, cocheros...-. Empero, el predominio fundamental recaía en los comerciantes, en especial, en ambas mayordomías, en los mercaderes al por menor, y más en concreto en los tenderos de joyería y especiería. Su cercanía a los problemas reales, y cotidianos, de la población, sus capacidades y habilidades monetarias y de contabilidad, sus apetencias de enriquecimiento, etcétera, les brindaban la ocasión, ansiada, de gestionar las propiedades del Común y de catapultarse, en la medida de lo posible, a mayores y mejores oportunidades. En muchos casos, contemplamos a estos individuos, y hogares, pugnando por auparse a mayordomías de mayor calado, a otros empleos de la Administración más y mejor pagados, y de gran alcurnia, y a la reivindicación de su extracción hidalga, a través del concurso de la Chancillería de Valladolid.

Se descubre, trabajo a trabajo, que la asunción de responsabilidades en las diversas mayordomías de la ciudad, sean municipales o sean de la Iglesia, no arrastraba a todos por igual. Existen "techos" de implicación que devienen de los niveles de fortuna y de los volúmenes de fianzas que eran capaces de captar. El Concejo, para asegurar la viabilidad de cada mayordomía, exigía, en ocasiones, más y más avales, según el caso, en especial a hogares de la pequeña nobleza o a los comerciantes al por mayor. A los tenderos se les daba, desde el gobierno municipal, más facilidades. El ser investidos con las responsabili- 
dades de la gestión de las mayordomías laicales -pósito y alhóndiga o Propios y arbitrios- o de las clericales -Mesa Capitular del Cabildo Catedral, Hospital de Barrantes, parroquias, conventos, monasterios, congregaciones, obras pías, etcétera- era, para muchos, deseado y aún sutilmente, clandestinamente, espoleado en las colaciones y barrios de la "República". La pobreza, y no solamente la de solemnidad, era incompatible con la asunción de estos quehaceres. Se precisaban volúmenes de rentas y niveles de fortuna que permitieran compatibilizar las actividades profesionales cotidianas con una circunstancia puntual, anual, el devenir de la mayordomía. Se zambullían en el control financiero de los bienes públicos municipales sin abandonar, en absoluto, sus particulares intereses laborales -en la mercaduría, en lo artesanal, en lo burocrático..., según el caso-. Se exponían a ciertos riesgos pero, con toda probabilidad, conseguían, merced a la exposición de sus identidades en la arena de la gestión pública, mucho prestigio, mayores patrimonios y niveles de vida y brillar con luz propia en la intrincada cultura de las apariencias de la Edad Moderna. Y, quizá, a la postre, ser "ojeados", en el "mundillo" de las redes de influencia, por los responsables de la Administración borbónica, precisados de disponer en cada vórtice de poder, por minúsculo que fuera, de hogares e individuos que materializaran la "hora navarra" en cada localidad"130.

\section{Bibliografía}

Ago, Renata, Il gusto delle cose. Una storia degli oggetti nella Roma del Seicento, Roma, 2006.

Aguirre Hueto, Jesús Manuel, "Reglamento del consejo de propios y arbitrios de la ciudad de Burgos (1763)", La ciudad de Burgos..., pp. 479-489.

Álvarez de Prado, Luís Alfredo, "Aportación al estudio de las haciendas concejiles castellanas. Los Propios y rentas de Burgos en el siglo XVIII", La ciudad de Burgos, Actas del Congreso de Historia de Burgos, Madrid, 1985, pp. 455-467.

Álvarez Santaló, León Carlos y García-Baquero González, Antonio, "La nobleza titulada en Sevilla, 1700-1834 (Aportación al estudio de sus niveles de vida y fortuna)", en Historia, Instituciones, Documentos, 7, Sevilla, 1980, pp. 125-167.

Álvarez Santaló, León Carlos y García-Baquero González, Antonio, “Los comerciantes de la Carrera de Indias en la Sevilla del siglo XVIII: el diseño notarial de sus fortunas y estatus", en García Hurtado, Manuel-Reyes (Ed.), Modernitas. Estudios en Homenaje al Profesor Baudilio Barreiro Mallón, La Coruña, 2008, pp. 273-308.

130. CARO BAROJA, Julio, La hora Navarra del XVIII (Personas, familias, negocios e ideas), Pamplona, 1969. 
Álvarez Santaló, León Carlos y García-Baquero González, Antonio, "Funcionalidad del capital andaluz en vísperas de la primera industrialización", en Estudios Regionales, 5, Sevilla, 1980, pp. 101-134.

Bartolomé Bartolomé, Juan Manuel y García Fernández, Máximo (Dirs.), Apariencias contrastadas: contraste de apariencias, León, 2012.

Bartolomé Bartolomé, Juan Manuel, Interiores domésticos y condiciones de vida de las familias burguesas y nobles de la ciudad de León a finales del Antiguo Régimen (1700-1850), León, 2017.

Belmonte López Huici, $M^{a}$ Carmen, Cuesta Martínez, Manuel, García Cano, $M^{a}$ Isabel y Pozas Poveda, Lázaro, "Las actas capitulares como fuente para la historia urbana", en La Ciudad Hispánica, siglos XIII al XVI, Madrid, 1987, pp. 39-68.

Bermúdez Aznar, Agustín, "El reformismo institucional ilustrado en el reino de Murcia durante el siglo XVIII", en Historia de la Región murciana, Murcia, 1984, volumen VII, pp. 79-105.

Campese Gallego, Fernando, Los representantes del Común en el Ayuntamiento de Sevilla (1766-1808), Sevilla, 2005.

Castillo Fernández, Javier, "'Negocios de familia": El perfil institucional y social de los mayordomos de propios del reino de Granada (1492-1550)", Crónica Nova, 31, 2005, pp. 23-64.

Cebreiros Álvarez, Eduardo, El municipio de Santiago de Compostela a finales del Antiguo Régimen (1759-1812), La Coruña, 1997.

Corral García, Esteban, El mayordomo de Concejo en la Corona de Castilla (s. XIII-s. XVIII), Madrid, 1991.

Cózar Gutiérrez, Ramón, Gobierno municipal y oligarquías. Los oficios públicos de la villa de Albacete en el siglo XVIII, Cuenca, 2008.

Cuesta Martínez, Manuel, Oficios públicos y sociedad. Administración urbana y relaciones de poder en la Córdoba de finales del Antiguo Régimen, Córdoba, 1997, p. 106.

Chaunu, Pierre, "Un nouveau champ pour I'histoire sérielle: le quantitatif au trosième niveau", en Métodologie de l'histoire et des sciencies humaines, Mélanges en I'honneur de Fernand Braudel, Toulouse, 1973, tomo II, pp. 105-125.

Dos Guimaraes Sá, Isabel y García Fernandez, Máximo (Dirs.), Portas adentro: comer, vestir, habitar (ss. XVI-XIX), Coimbra-Valladolid, 2010.

Fayard, Janine, Los miembros del Consejo de Castilla (1621-1746), Madrid, 1982 y "Fortune et hiérarchie au Conseil de Castille aux XVIle et XVIIle siècles: Les Arce et les Medrano", I Jornadas de Metodología Aplicada de las Ciencias Históricas, Madrid, 1975, volumen 3, pp. 541-550.

Franco Rubio, Gloria (Ed.), La vida de cada día. Rituales, costumbres y rutinas cotidianas en la España Moderna, Sevilla, 2012. 
García Fernández, Máximo, "La cultura material doméstica en la Castilla del Antiguo Régimen", en García Fernández, Máximo y Sobaler Seco, Ma Ángeles (Coords.), Estudios en homenaje al profesor Teófanes Egido, Valladolid, 2004, vol. II, pp. 249-270.

García Fernández, Máximo (Dir.), Cultura material y vida cotidiana moderna: escenarios, Madrid, 2013.

García García, Carmen, "Haciendas municipales y bienes de propios: Las reforma de Carlos III", Anales de estudios económicos y empresariales, 1, 1986, pp. 89-114.

Gómez Martínez, Alfredo, "Cargos y oficios municipales en las ciudades de León, Zamora y salamanca durante el reinado de Carlos III", Estudios Humanísticos, 5, 2006, pp. 159-184.

González Cruz, David, Religiosidad y ritual de la muerte en la Huelva del siglo de la llustración, Huelva, 1993, pp. 21-22.

González Heras, Natalia, Servir al rey y vivir en la corte: propiedad, formas de residencia y cultura material en el Madrid borbónico, Madrid, 2014.

González Sánchez, Carlos Alberto, El mundo del libro. Medios de difusión de la cultura occidental en las Indias en los siglos XVI y XVII, Sevilla, 2001, p. 26.

Guerrero Mayllo, Ana, Familia y vida cotidiana de una elite de poder: los regidores madrileños en tiempos de Felipe II, Madrid, 1993.

Guerrero Mayllo, Ana, Oligarquía y gobierno municipal en la corte de la monarquía hispánica: el concejo de Madrid entre 1550 y 1606, Madrid, 1991.

Guillamón Álvarez, Francisco Javier y Pérez Hervás, Jesús, “Aproximación al estudio de las haciendas locales bajo Carlos III: Los propios del concejo murciano", Espacio, Tiempo y Forma, Historia Moderna, 4, 1989, pp. 341-356.

Gutiérrez Alonso, Adriano, Estudios sobre la decadencia de Castilla. La ciudad de Valladolid en el siglo XVII, Valladolid, 1989.

Gutiérrez Alonso, Adriano: "La hacienda municipal de Burgos en la época moderna. Los bienes de propios (1500-1750)", Boletín de la Institución Fernán González, 215, pp. 327-354.

Hernández Benítez, Mauro, A la sombra de la Corona: poder y oligarquía urbana (Madrid, 1606-1808), Madrid, 1995.

Hernando Ortego, Francisco Javier, El patrimonio municipal de Madrid en el Antiguo Régimen. Bienes de propios, comunales y baldíos, siglos XI-XVIII, Madrid, 2003.

Hernando Serra, $M^{\text {a }}$ Pilar, "Un siglo de reformas: Haciendas municipales y Reglamentos en la Valencia del XVIII", AHDE, 83, 2013, p. 550.

Hernando Serra, $M^{a}$ Pilar, "Un siglo de reformas: Haciendas municipales y Reglamentos en la Valencia del XVIII", $A H D E, 83,2013$, pp. 543-568. 
Imízcoz Beunza, José $M^{a}$ (Dir.), Redes familiares y patronazgo. Aproximación al entramado social del País Vasco y Navarra en el Antiguo Régimen (siglos XV-XIX), Bilbao, 2001.

Imízcoz Beunza, José Ma (Dir.), Elites, poder y red social. Las élites del País Vasco y Navarra en la Edad Moderna, Bilbao, 1996.

Imízcoz Beunza, José Ma y Oliveri Korta, Oihane (Eds.), Economía doméstica y redes sociales en el Antiguo Régimen, Madrid, 2010.

Irles Vicente, $\mathrm{M}^{\mathrm{a}}$ Carmen, El régimen municipal valenciano en el siglo XVIII. Estudio institucional, Alicante, 1995.

Lick, Richard, "Les intérieurs domestiques dans la seconde moitié du XVIIle siècle d'après les inventaires après décès de Coutances", en Annales de Normadie, 20, Caen, 1970, pp. 293-315.

Madureira, Nuno, Cidade: Espaço e quotidiano (Lisboa, 1740-1830), Lisboa, 1992.

Marina Barba, Jesús, Poder municipal y reforma en Granada durante el siglo XVIII, Granada, 1992.

Maruri Villanueva, Ramón, La burguesía mercantil santanderina, 1700-1850 (Cambio social y de mentalidad), Santander, 1990.

Moreno Claverías, Belén, Consum i condicions de vida a la Catalunya Moderna. El Penedés, 1670-1790. Barcelona, 2007.

Moreno Claverías, Belén, "Pautas de consumo y diferenciación social en El Penedés a fines del siglo XVII. Una propuesta metodológica a partir de inventarios sin valoraciones monetarias", en Revista de Historia Económica, $N^{\circ}$ extraordinario, Madrid, 2003, pp. 207-245.

Moreno Nieves, José A., "Estudio de la hacienda municipal a través de los libros de propios de la ciudad de Villena (1708-1766)", Revista de Historia Moderna, 13-14, 1995, pp. 207-229.

Pardailhe-Galabrun, Annik, La naissance de l'intime. 3000 foyers parisiens. XVIle-XVIIle siècles, París, 1988.

Porres Marijuán, $M^{a}$ Rosario, Gobierno y administración de la ciudad de Vitoria en la primera mitad del siglo XVIII (Aspectos institucionales, económicos y sociales), Vitoria, 1989.

Porres Marijuán, Rosario (Dir.), Aproximación metodológica a los protocolos notariales de Álava (Edad Moderna), Bilbao, 1996.

Ramos Palencia, Fernando, Pautas de consumo y mercado en Castilla, 17501850. Economía familiar en Palencia al final del Antiguo Régimen, Madrid, 2010.

Roche, Daniel, Histoire des choses banales. Naissance de la consommation (XVIIe-XIXe siècles), París, 1997.

Roche, Daniel, La culture des apparences. Une histoire du vêtement (XVIleXVIIle siècles), París, 1989. 
Rubio Pérez, Laureano, "Haciendas concejiles y haciendas municipales en la provincia de León durante la Edad Moderna", en Bernardo Ares, José Manuel (Coord.), V Reunión Científica de la Asociación Española de Historia Moderna, Cádiz, 1999, tomo II, pp. 275-289.

Salgado Olmeda, Félix, Oligarquía urbana y gobierno de la ciudad de Guadalajara en el siglo XVIII (1718-1788), Madrid, 2000.

Sanz de la Higuera, Francisco, "Las "restauraciones" del Consulado de Burgos en el siglo XVIII", Historia, Instituciones, Documentos, 29, 2002, pp. 429458.

Sanz de la Higuera, Francisco, "Pólvoras, municiones, lanas, granos, bulas y papel sellado (1703-1764): Don Pedro Tomé González y la hora Navarra en el Burgos del siglo XVIII", Boletín de la Institución Fernán González, 227, 2003, pp. 375-411.

Sanz de la Higuera, Francisco, "Un esperpéntico asuntillo de Estado: La casa de los Tomé en el Setecientos burgalés", en Cuadernos de Estudios del Siglo XVIII, 21, Oviedo, 2011, pp. 287-318.

Sanz de la Higuera, Francisco, "Los mayordomos de la Mesa Capitular de la Catedral de Burgos en el Setecientos (1707-1782)", Trocadero, 25, 2013, pp. 117-146.

Sanz de la Higuera, Francisco, "La cultura material de los tesoreros generales de la Santa Cruzada en el Burgos del XVIII", Cuadernos de Estudios del siglo XVIII, 25, 2015, pp. 317-336.

Sanz de la Higuera, Francisco, "Aproximación a la mayordomía del Hospital de Barrantes en el Setecientos burgalés (1702-1797)", Trocadero, 28, 2016, pp. 51-77.

Sanz de la Higuera, Francisco, "Cultura material de los mayordomos del pósito y "Lóndiga" en el Burgos del Setecientos", Boletín de la Institución Fernán González, 257, 2018, pp. 307-325.

Sanz Yagüe, Ana Isabel, La ciudad de Soria en el siglo XVIII. Un estudio sociocultural, Soria, 2012, Representación política y participación directa. El "policentrismo" político de Soria y la supervivencia del estado del Común en el siglo XVIII, Madrid, 2018.

Sanz Yagüe, Ana Isabel, "Patrimonio, cultura material y diferenciación social en la ciudad de Soria durante el siglo XVIII", Nuevo Mundo Mundos Nuevos [En línea], Coloquios, 2008 -consultado el 1 de noviembre de 2018-. URL: http://journals.openedition.org/ nuevomundo/22902.

Sanz Yagüe, Ana Isabel, Representación política y participación directa. El "policentrismo" político de Soria y la supervivencia del estado del Común en el siglo XVIII, Madrid, 2018.

Sarti, Raffaela, Vida en familia. Casa, comida y vestido en la Europa Moderna, Barcelona, 2002. 
Shammas, Carole, The Pre-industrial Consumer in England and America, Oxford, 1990.

Sobrado Correa, Hortensio, "Los inventarios post-mortem como fuente privilegiada para el estudio de la historia de la cultura material en la Edad Moderna", Hispania, 215, 2003, pp. 825-862.

Torres Sánchez, Rafael, "Hacia un irremediable endeudamiento. La hacienda municipal de Cartagena durante el siglo XVIII", en Pereira Iglesias, José Luís, Bernardo Ares, José Manuel y González Beltrán, José Manuel (Coords.), $V$ Reunión Científica de la Asociación Española de Historia Moderna, Cádiz, 1999, tomo II, pp. 289-307.

Waro-Desjardins, Françoise, La vie quotidienne dans Le Vexin au XVIIIe siècle. Dans l'intimité d'une société rurale, Condé-sur-Noireau, 1992.

Waro-Desjardins, Françoise, "Permanences et mutations de la vie domestique au XVIIle siècle: Un village du Vexin français", en Revue d'histoire moderne et contemporaine, 40, París, 1993, pp. 3-29.

Weatheril, Lorna, Consumer Behaviour and material culture in Britain, 16601760, Londres-Nueva York, 1988. 